\title{
Assessment for Intervention of Children with Fetal Alcohol Spectrum Disorders: Perspectives of Classroom Teachers, Administrators, Caregivers, and Allied Professionals
}

\author{
Jacqueline Pei, Jenelle M. Job, Cheryl Poth, Erin Atkinson \\ Department of Educational Psychology, University of Alberta, Edmonton, Canada \\ Email: jacqueline.pei@ualberta.ca
}

Received December 21 $1^{\text {st }}$,2012; revised January 21 ${ }^{\text {st }}$, 2013; accepted February $17^{\text {th }}, 2013$

\begin{abstract}
The present study begins to address the need for evidence-based approaches for guiding the psychological assessment of children with Fetal Alcohol Spectrum Disorders (FASD). This project represents an important step toward increasing links between research and practice in the communication and use of assessment results for informing intervention decisions. Using a qualitative research approach, the current study contributes to knowledge about concerns with current psychological assessment practices and offers suggestions for optimization based on conversations with teachers, administrators, caregivers and allied professionals. Thematic analysis of 11 focus groups and 3 interviews $(N=60)$ yielded 3 major findings: the need to focus on the whole child, the necessity of an assessment process that is responsive, and building capacity in the school. This study increases the links between research and practice as we move toward a model of assessment for intervention. Such a model has a strong potential for optimizing assessment practices to better meet the needs of children with FASDs as it promotes a shift that focuses on successful child outcomes regardless of diagnosis.
\end{abstract}

Keywords: Fetal Alcohol Spectrum Disorders; Assessment; Intervention; Supports and Resources; Children; Focus Group

\section{Introduction}

Fetal alcohol spectrum disorders (FASDs) are a serious health and social concern (Chudley et al., 2005). FASDs are the result of maternal alcohol consumption during pregnancy and have significant implications for the affected person, mother, family and community due to lifelong deficits in several domains of brain function (Chudley et al., 2005). Although literature regarding the behavioral profile of individuals with FASDs is relatively limited (Burd, Klug, Martsolf, \& Kerbeshian, 2003), reported neuropsychological and social deficits include cognitive delay, poor executive functioning, limited social awareness, weak adaptive skills, and mental health issues (Burd et al., 2003; Harris, MacKay, \& Osborn, 1995; Kelly, Day, \& Streissguth, 2000; Pei, Denys, Hughes, \& Rasmussen, 2011; Rasmussen, 2005; Steinhausen, Willms, Metzke, \& Spohr, 2003). These substantial impairments create daily challenges for individuals living with FASDs. These difficulties can be lessened with appropriate interventions and supports that are especially effective when implemented in a way that involves collaboration among those involved in the child's life across home and school.

The school experience is often significantly impacted for children with FASDs given the frequent presence of specific cognitive and academic difficulties (Howell et al., 2006) as well as behavioral problems. Given the disorder's diverse presentation, there is a strong potential for school personnel to misunderstand the affected child; thus, it is unsurprising that many children do not receive the empathy or accommodations they require and may become frustrated and contemplate leaving school (Duquette, Stodel, Fullarton, \& Hagglund, 2006a). Nonetheless, promising research has shown that given the right environment and support, adolescents with FASDs can graduate from high school (Duquette, Stodel, Fullarton, \& Hagglund, 2006b) and go on to lead fulfilling and quality lives (Ackerman, 1998; Green, 2007; Ryan \& Ferguson, 2006a, 2006b). Therefore, the critical role of appropriate interventions and supports for these children cannot be underestimated.

\section{Assessment versus Intervention}

Psychological assessment is often the first step in the development and implementation of appropriate interventions for children with a variety of psychological and educational needs, including those with FASDs (Kalberg \& Buckley, 2007). The array of symptoms and deficits associated with FASDs lends itself to the need for comprehensive assessments that identify the affected child's strengths as well as highlight weaknesses requiring additional support. This information aids teachers and allied professionals to implement suitable programming and provide meaningful accommodations. Although often a helpful and key part of the intervention process, current assessment practices are not without their limitations. In fact, a general dissatisfaction with current psychological assessment and report writing practices has been noted for more than four decades, although little has been done to improve practices and remedy these concerns (Mastoras, Climie, McCrimmon, \& Schwean, 2011). Teachers, parents, and other service providers involved in working with children with a variety of special needs and educational requirements continue to express concerns about 
test administration, report writing, and communication of the results.

Foremost, psychological assessments have been criticized as being disconnected from the interventions they are intended to inform. Examining the usefulness of assessment reports, Knoetze and Vermoter (2007) conducted focus group interviews with 10 remedial teachers in South Africa. These discussions revealed 3 important findings related to the lack of collaborative practice in current assessment practices. First, teachers reported a gap between the psychologist's assessment expertise and his/ her practical knowledge of the classroom environment including teaching strategies and interventions. Second, it was shown that although teachers respect the skills psychologists bring to the assessment process, they believe that they too possess expert knowledge on classroom interventions and should be consulted with when making decisions about programming. Lastly, teachers noted that their input is rarely sought when recommendations are written, resulting in suggestions that have already been attempted by the teacher or that are unrealistic for the classroom. The disconnect between the potential usefulness of assessment and the reality of current assessment practices serve as an impetus for the present study.

\section{Understanding Reports}

An essential precursor for educational strategies is that teachers and parents have access to useful psychological reports (Borghese \& Cole, 1994). In particular, a report is useful when it is easily understandable (e.g. Cheramie, Goodman, Santos, \& Webb, 2007), when information is sufficiently specific to drive interventions (Ryan \& Ferguson, 2006a), and when strengthbased language is used in addition to highlighting weaknesses. Researchers have reported that the language used in reports (e.g., technical jargon) and the time it takes to decipher recommendations often frustrates teachers and parents (Cheramie et al., 2007; Knoetze \& Vermoter, 2007). Workload issues restrict the time teachers have available to read and understand a psychological report. For parents, limitations in education and reading ability pose a challenge for genuine understanding (Harvey, 1997), which can lead to feelings of detachment from the assessment process and impede recommendation follow-through and advocacy (Groth-Marnat, 2009). Despite numerous suggestions for the improvement of psychological reports, specialized reports full of complex language continue to be produced (Harvey, 2006; Mastoras et al., 2011).

Even when report language is not a concern, teachers often feel that the way in which reports are written is too general (Ryan \& Ferguson, 2006a), and does not focus enough attention on the identified issue(s). Often teachers feel as though they need to perform their own evaluations after receiving the report to pinpoint specific areas needing support (Knoetze \& Vermoter, 2007). Ultimately, the purpose of psychological assessment is to aid in the planning and implementation of individualized interventions focused on improving functioning and achievement (Fletcher et al., 2002); however, if the reports generated address concerns in too broad a manner then their relevance and value are compromised.

Another concern is the continued dissatisfaction with deficitfocused language used consistently in reports (Groth-Marnat, 2009). Assessments often focus on what the child cannot door what they struggle to do-rather than suggesting areas in which they demonstrate strengths (Mastoras et al., 2011). And yet, research has found that including personal and educational strengths in a psychological report can have a significant therapeutic effect, and that focusing ability rather than solely disability can lead to more efficacious treatment recommendations and long-term growth (Seligman, Linley, \& Joseph, 2004). Providing teachers with information about the strengths a child possesses and how these can be used to compensate for learning and behavioral difficulties may help them to tailor and implement interventions that have the capacity to facilitate change. This may serve to lessen the educational frustrations of the affected child as well as relieve some pressures from teachers to modify programming without appropriate understanding of what will work best.

\section{Assessment for Intervention}

Taken together, the limitations associated with current assessment practices often lead to confusion and frustration for teachers and allied professionals working with children with FASDs who present with varied psychological, behavioral, and educational needs. Overall, these concerns are not unique to the assessment of children with FASDs but exist for evaluations of children across contexts, ability levels, and cultures (e.g., Knoetze \& Vermoter, 2007), demonstrating global challenges with psychological assessment and its usefulness for intervention determination. While the implications of less-than-optimal assessment practices are far-reaching and affect a number of people, they are especially troubling for children who present with involved psychological profiles such as those with FASDs. Given this complexity, the problems created by inefficient and inadequate diagnostic-driven assessment practices are magnified. The time for a move to assessment for intervention has come.

\section{Purpose and Objectives}

The present study is part of a larger program of research focused on improving educational practices for children with FASDs (see Job et al., 2013; Pei, Job, Poth, O’Brien-Langer, \& Tang, 2013; Poth, Pei, Job, \& Wyper, 2013). This study addresses the call for increasing the voice of teachers, administrators, caregivers, and allied professionals (i.e. social workers, counselors, and educational assistants) in research related to school-based interventions and supports. In particular, our findings report on the assessment experiences of key stake-holders involved in the implementation of interventions and support services for children with FASDs (Job et al., 2011).

With a goal to inform school psychology practice, this study was guided by the following 3 objectives: a) examine the positive and negative assessment experiences and attitudes of teachers, administrators, caregivers, and allied professionals working with children with FASDs; b) determine whether the experiences of these stakeholders are consistent with the general themes of dissatisfaction identified in the assessment literature; and c) propose solutions to current psychological assessment approaches considering the suggestions of key stakeholders, and linking them to emerging research and evidence-based practice in the field.

\section{Methods}

A qualitative, phenomenological approach was appropriate given the study's purpose to generate a comprehensive under- 
standing of experiences to inform practical next steps (Creswell, 2013). Semi-structured focus groups were selected as the means for data collection as this allowed researchers to capture individual stakeholder perspectives as well provide a forum for participants to meet others who had experienced similar struggles in the pursuit of diagnostic testing and specialized supports. This interaction also provided those who had faced considerable obstacles with hope when listening to others' stories of successful assessment and intervention. Data collection for this study follows the call for an increased presence of stakeholders' perspectives in educational research involving children with FASDs (Duquette et al., 2006a), facilitating a deeper understanding of the issues in assessment and roles involved parties play in navigating the process (e.g., facilitator of the assessment, recipient of report results, and communicator of the information) (Krueger \& Casey, 2000). For stakeholders unable to attend focus group times, interviews were conducted following the same protocol. Trustworthiness and confidence in the data was enhanced by the use of verbatim transcripts, member checking of focus group and interview summaries, and multiple coders (Merriam, 2009; Patton, 2002).

\section{Participants}

A total of 60 individuals participated in the present study including 31 teachers, 7 administrators, 16 allied professionals, and 6 caregivers. Teachers reported having a degree of expertise in special education, a mean of 13.2 years of experience (range 1 - 32 years), and representing all levels of instruction (7 identified as Kindergarten to grade 5 and 24 identified as grade 6 to 12). Administrators had a mean of 22 years of experience (range 15-30 years) within various roles (2 principals, 4 assistant principals, and 1 head of student services). Allied professionals reported a mean of 10.89 years of experience (range 1 25 years), with the majority (12) identifying their roles as educational assistants and the remaining as other (i.e., in-home consultant, reading specialist, guidance counselor, and manager of the school's Academy of Reading \& Math Programs). Caregivers consisted of 2 maternal grandmothers, 3 foster mothers, and 1 adoptive mother. Their mean years of experience ranged from 6 to 43 with a mean of 17.83 years. The age range for affected children with whom the stakeholders worked was 3 to 18 years.

\section{Data Collection}

Participant recruitment was ongoing from March 2009 to May 2012, using snowball sampling through established clinical networks via email and telephone. Allied professional and caregiver participants were identified through their involvement with local FASD networks and programs. Administrator and teacher participants were identified based on FASD student population. Criteria for participant selection included: a) experience with a child with an FASD; b) involvement in that child's psychological or neuropsychological assessment (e.g., completing forms, providing an interview, being provided with assessment results, and/or implementing interventions based on report recommendations); c) working with that child in the classroom or having knowledge of his/her classroom experience; and d) communicating with caregivers, administrators, teachers, and/or allied professionals in support of successful outcomes.

In total, 11 focus groups and 3 individual interviews by role (i.e., teachers, caregivers) were held, each lasting approximately one hour and following a semi-structured protocol. Regardless of whether stakeholders participated in focus group or interview sessions, the same protocol and probes were employed, with minor adaptations to reflect role-specific experiences. For example, the question, "What supports outside the school system have you accessed to help your child?" was asked solely of caregivers to provide information about community supports and resources. The number of focus group participants ranged from 2 to 9 with a mean of 6 . Two research assistants (interviewer and note-taker) with advanced training in qualitative research facilitated the sessions. The presence of a note-taker allowed the interviewer to remain fo- cused on the interview process. Discussions were audio recorded and transcribed verbatim, and a preliminary analysis generated summaries that were distributed to participants electronically as a means of member checking (Creswell, 2012). Participant feedback and additional comments were incorporated as notes in the transcriptions to ensure accuracy of the data and completeness of participant response.

\section{Data Analysis}

Inductive analysis was undertaken in 3 phases: individual focus groups and interviews, across focus groups and interviews involving the same roles, and finally a cross-analysis of focus groups, interviews, and roles. The integration of data sources was guided by a constant comparison approach (Glaser \& Strauss, 1967) wherein codes and categories across focus groups were compared for both congruence and dissonance by two independent researchers. Researchers began by generating codes for one transcript, and then adding on or modifying codes across transcripts within the same roles. Codes were discussed until consensus was reached with the aim of achieving interrater reliability of $90 \%$. Code definitions were informed after reading all transcripts.

At the end of this process, codes were pared down and assigned to broader categories. Summaries were written for each role and helpful during the cross-analysis, allowing researchers to compare similarities within each role and highlight differences across roles. This allowed for further streamlining of the code and category lists and allowed for the identification of themes and subthemes (see Figure 1) with definitions. Complete coding lists demonstrating the progression from codes to themes were created for each role and then integrated as much as possible into a master list across roles. Important data specific to one role were starred and discussed separately within the findings.

\section{Findings and Discussion}

Thematic analysis yielded 3 major findings which focused on: the whole child, the assessment process, and building school capacity. Interestingly, findings revealed that concerns with and goals for improved assessment processes were not limited to the FASD population but rather all children. The high needs of children with FASDs simply serve to draw attention to the importance of such changes. The following section is organized by theme illuminating key concepts and experiences.

\section{The Whole Child}

Increasing the scope of the assessment process, to reflect the 


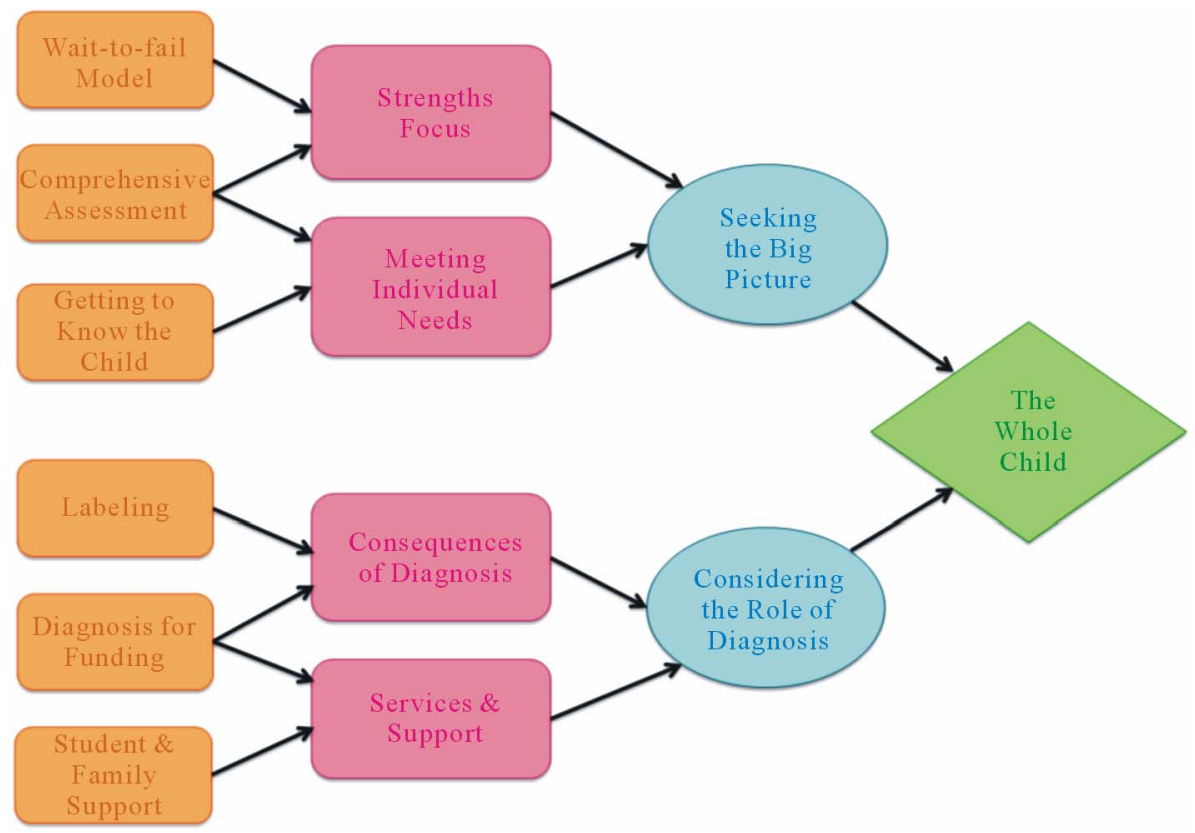

Figure 1.

An example of code and theme development across roles.

whole child, emerged as a necessary initiative in the move toward improving diagnosis and intervention. To do this, participants felt that the information gathered must be sufficiently comprehensive to reflect the complex needs of this population. The goal of psychological assessment for diagnosis was questioned, with the rationale that there is a role for diagnosis within the assessment process to help initiate funding, but that the process can consist of more than the diagnosis alone. In short, two key ideas were detailed: seeking the big picture through a more collaborative and thorough assessment process and considering the role of diagnosis as a vehicle for resources and support.

Seeking the big picture. The process of gathering information from multiple sources was consistently noted as being foundational to the validity of the assessment process across caregiver, administrator, and allied professional roles. The need for more comprehensive assessments involving multiple individuals and data sources was emphasized in contrast to making a determination for diagnosis and intervention based on limited information. Wynn, an administrator, discussed the process of assessment at her school: "Our psychologist meets with us, gathers the information, [and] observes the kids on two or three days..." The advantages of such a process include a better understanding of the child's strengths and weakness across settings, which enhances the likelihood that the assessment will inform meaningful and feasible interventions, rather than “... just getting a one-hour snapshot”.

A disconnect within the process of integrating the assessment data to inform intervention decisions and practices was viewed as being a source of concern as was the quality of written psychological reports. Currently, assessment seems to be focused on the product (i.e. producing a psychological report) rather than the process of collaborating and involving all individuals who care for the child in order to understand his or her needs. For high-needs populations such as children with FASDs, consistency in assessment process and practice has been revealed in the literature as being key to implementing well-suited interventions. Ensuring all individuals involved in caring for children with FASDs have the same information and understanding, and considering their suggestions and feedback in the assessment and intervention processes is crucial (Blackburn, Carpenter, \& Egerton, 2010).

Similar to the call for the inclusion of multiple sources in assessment, participants across all four roles indicated a desire for the incorporation of information useful to strengths-based programming. Caregivers and allied professionals discussed the hindrance of a deficit-model, which emphasizes areas of weakness and perpetuates stigma and stereotypes. The use of a deficit-model proved common in the assessment experiences of participants across roles with only one caregiver experiencing a supportive and strengths-based evaluation: “... [the assessment proved] very supportive...the girl from the psych report [explained] his areas of strength and weakness and learning style...so that they could make accommodations for him” (Jessica).

All participants agreed on the usefulness of information about cognitive and academic strengths in developing appropriate interventions, noting that having the complete learning profile of a child with an FASD leads to greater success in programming and achievement. Concentrating on deficits may enable school psychologists to diagnose disabilities but such practice does not inform intervention and treatment of difficulties (Jimerson, Sharkey, Nyborg, \& Furlong, 2004). Conversely, researchers posit that identifying areas of strength (e.g., confidence) may help to address underlying challenges rather than simply managing observable behaviors (Terjesen, Jacofsky, Froh, \& DiGiuseppe, 2004). The use of a strength-based approach also allows school psychologists and educators to better understand affected children and their resources, facilitating more complete intervention planning (Rhee, Furlong, Turner, \& Harari, 2001).

Considering the role of diagnosis. When considering the 
consequences of diagnosis for a child with an FASD, caregivers discussed diagnosis as a vehicle for accessing resources. Caregivers tended to view diagnosis as a strength allowing them access to services and accommodations that were previously unavailable rather than a label that would negatively affect their child:

"I felt it's more important that the child gets help than worry about a label...I gave the school copies of all the reports that we had...in fact one of the teachers said to me, 'I'm so grateful to you for communicating this with us. You'd be surprised how many parents don't want us to know the children have some problem.”' (Jessica, Caregiver)

Darlene, a caregiver, added that diagnosis provides support in advocating for specialized programming and resources:

"some of the positive things about having a diagnosis is you've got something to work with and you've got back up. [If] you've got that piece of paper in your hand, then you don't have to back down from anyone”.

For school personnel, diagnosis was viewed as more of a guide, affording children and families greater direction and support. As Wynne, an administrator, explained:

“...quite often if the child has FAS, there's a good chance the [biological] family is. So, they don't have the structure. They don't have the ability to come in and share their experiences since schools have not been good...quite often they avoid the school. They're not coming in there advocating...so, it's helping them also."

Caregivers may fear assessment and diagnosis for their child believing that it can lead to differential treatment by teachers, peers, and even other family members. However, receipt of a diagnosis can have value, providing a way to identify the affected child's difficulties and abilities and plan for problems that may arise in future educational endeavors (Temple University Institute on Disabilities [TUID], 2003). A diagnosis can also be beneficial in linking children and families with funding and specialized programs and affording them access to services crucial to success and healthy child development (TUID).

One of the main concerns with either a lack of psychological assessment or less-than-optimal assessment practices is that affected children may be misunderstood, resulting in inadequate or inappropriate educational support. Tom, an administrator, explained this challenge: “...quite often we don't know because they haven't been formally diagnosed and they've been going through school for many years you know being seen as behavior students..." However, receiving a diagnosis may not be enough for improved understanding of FASD, especially considering the diverse presentation of the disorder in affected children. As Chloe, a caregiver, so eloquently expressed: “... regardless of whether it's the same label, they are different children....and that's what...people have to look at. Just because everybody has the same label doesn't mean everybody's the same person." Therefore, the utility of assessment and diagnosis appears hedged in how well teachers, administrators and allied professionals are prepared to work with children with FASDs and how informed they are about the condition.

Despite efforts to differentiate between diagnostic labels and better inform teachers of the disorder (Chudley et al., 2005), such attempts do not necessarily translate into improved teacher knowledge of what challenges he/she may see in the classroom (Clark, 2012). This is why professional development and resources specific to FASD are essential for school personnel and allied professionals working with affected children. In instances where the needs of the child with an FASD are well understood, stakeholders can work collaboratively to provide necessary services, as in the case of Laura, a caregiver:

“...we got [the assessment] nice and early...this is what allowed us to have all this wonderful help...our grandson was given two years in kindergarten and he had occupational therapists and physiotherapists. He had all sorts of things coming into the room because he was eligible for it...early on someone [was] coming to the house to work with him at home...everything was really good but it was all based on that diagnosis.”

Researchers have established the importance of accurate diagnosis in determining appropriate interventions and limiting the effects of secondary conditions (Malisza et al., 2005). However, diagnosis necessitates a response that includes the development of a network of support and program planning tailored to the affected child's specific needs (Public Health Agency of Canada, 2011). Whereas caregivers can help with advocacy and modeling, school psychologists and educators can have an influence through creating and following individualized program plans, establishing smooth transitions, and collaborating with caregivers and community members (Duquette et al., 2006a). Findings from the present study would suggest that while we are striving toward a more collaborative, supportive model of diagnosis and intervention, there is still work to be done.

\section{The Assessment Process}

The assessment process itself also emerged as an area of conversation with participants. Many of these discussions seemed linked to the underlying philosophy that accompanies psychological assessment. Assessments may often be seen as a way to react to concerns by identifying the problems that are present. However, what this perspective fails to do is provide any proactive response options with consideration for both deficits and strengths with a goal toward identifying what success might look like rather than solely why there is failure (Klin, Saulnier, Tsatsanis, \& Volkmar, 2005). Consequently, two key ideas emerged: responsiveness of the assessment to prevent the occurrence of greater problems and finding success by ensuring professionals are equipped to help affected students achieve success.

Responsiveness. Participants spoke about the logistical components of the assessment process as they contribute to practices that are deficit-focused and reactive due to the boundaries of process (e.g., delay in achievement must be demonstrated before an assessment can be requested). Consequently, they emphasized the need for the process to be responsive to children, educators, and families in order to effectively address learning and behavioral needs and concerns with an eye toward success rather than simply reducing problems. Paramount to this idea is offering assessment services that are timely and accessible. For some participants, the assessment process was smooth and allowed for timely receipt of diagnosis and recommendations, as evidenced by one caregiver, Jessica's account:

“...I requested [a psycho-educational assessment] for him and they were more than willing [to do it] right away, no 
questions asked...I didn't have to fight for it. I didn't have to justify why I wanted it. They were just willing to do it...[and] they had the psych[ological] report done right away."

For others, the wait for an assessment across school and community settings was long yet worthwhile. As Laura, a caregiver noted, “...it takes a number of months to get in [for an assessment]...but it was a very smooth process once we started it. And then there's a whole team of professionals that work with these kids." This experience was echoed by school personnel who reported lengthy waits for an assessment due to psychologists' full caseloads: “...even the assessments that do get done at school...they are well done but they're a very lengthy process" (Nadia, Allied Professional).

Overall, stakeholders underscored the benefits of early assessment by qualified professionals. One teacher specified that a "good, accurate assessment would be really [helpful] to get all the testing done quickly and...by the right people” (Jenna). Working toward an assessment model that allows for early and timely diagnosis and intervention information enables the child with an FASD access to funding for programmatic changes and resources, focusing on growth rather than struggle (Healthy Child Manitoba, 2010).

Equally as detrimental as the wait time identified by teacher and administrators was the wait-to-fail model wherein assessments cannot be accessed until a consistent lack of achievement is shown. Wynne, an administrator, described her view of this system and ideas for improvement:

“...it's kind of frustrating 'cause they now have experienced 3 years of failure because they have to be 2 years behind before they actually get identified. If we can identify them earlier then the school can be set up so that they're helping...streamline them into a special education program if they need or at least [let] the teachers adapt...”

Evidence of the benefits of early diagnosis (e.g., improved care of primary deficits and decreased impact of secondary disabilities) is well documented (Koren, Nulman, Chudley, \& Loocke, 2003; Streissguth \& Kanter, 1997) as a useful way to reduce later adverse outcomes. However, some children with PAE meet developmental milestones at age-appropriate times and thus, an assessment at one time point may not provide a comprehensive picture of functioning. For instance, it is only when neurobehavioral deficits arise, including impairment in executive functioning, that information about independent functioning can be gleaned (Koren et al., 2003; Rasmussen, 2005). Therefore, it may be prudent to think of assessment as not simply a diagnostic task but rather a way of gathering ongoing information about a child at key points in their education (e.g. transitional times) to facilitate interventions that adapt to the affected child's changing needs and abilities. It is apparent that too much of a delay for treatment (i.e., the wait-to-fail model or time lags) can lead to a population of students who fall farther and farther behind their classmates (Fletcher et al., 1998).

Finding success. Finding success through psychological assessment means gaining understanding about where a child is at and what would help to address his/her individual needs in order to work toward success. For school personnel, this requires adaptation, flexibility, and knowing your students. As one allied professional, Bob explained:

$$
\text { “...it really depends on the kid. If the kid's capable }
$$

then...we push to achieve... but I think that I really try to be what the kid needs...it's trying to see what's going on, what are the motivations behind what he's up to, and... then trying to provide him what he needs..."

However, part of achieving this degree of flexibility is dependent on the team that participates in the assessment process. It is imperative that the psychologist in charge of the assessment recognizes that it will require a team to develop comprehensive intervention strategies and that the process warrants contribution at all stages. As one teacher noted, intervention planning is best done in collaboration:

\section{“...the support makes you stronger as a teacher too, right?...I learn so much from a [speech language patholo- gist] and an [occupational therapist] and you learn so many tricks [about] how they modify [things]...they come in and they add something new and it just gets better and better and you get stronger that way and more confident in [your teaching]" (Carla).}

Participants stated that it is not enough just to have professionals and families communicate with one another regarding needs and strategies, but that children with FASDs require active collaboration to identify needs and strengths and establish effective strategies. This is commensurate with previous research that emphasizes caregiver involvement in school-based interventions (e.g., Clark, 2012; Kalberg \& Buckley, 2007). Such an approach will help with skill building, the improvement of cognitive and learning strategies, and the reinforcement of positive behaviors as well as involve families in the process of advocating for needed and warranted services for their children and themselves. Assessments geared toward intervention can provide the catalyst and guidance for this degree of collaboration.

All participant groups called for increased support for teachers and caregivers from administration and other professionals (e.g., social workers, counselors, and mental health professionals) so as to enhance the understanding of children with FASDs and increase the utility of assessment. A teamwork approach was described as a necessity whereby the workload is distributed among different stakeholders to ensure that affected children receive needed assessments in a timely manner and that shared understandings are reached. To assist in the provision of interventions for children with FASDs, it is essential that professionals working with this population receive adequate training and information about FASD-related deficits and secondary disabilities, including the condition's diverse presentation and best practices for assessment and intervention (Gahagan et al., 2006; Green, 2007; Paley \& O’Connor, 2009; Paley et al., 2009).

\section{Building School Capacity}

If a psychological assessment is to draw nearer to improved understanding geared toward creating success for the whole child-within assessment activities as well as through the assessment process-then it is crucial that the assessment not stand-alone. Instead, strong links between stakeholders and effective communication strategies are important. To this end, stakeholders emphasized the importance of a third theme focused on building school capacity in which two related challenges of the assessment process are emphasized: 1) clarity of written communication that fosters understanding and facili- 
tates the development of interventions; and 2) transferring assessment information to key stakeholders in a way that enables implementation of useful recommendations for increased learning and development.

Information sharing. The discussion about assessment reports centered around two unique topics: ease of sharing assessment results with school personnel and difficulty in understanding report content. With respect to the former, it appears schools are quite willing to receive assessment results and better understand the affected child's strengths and weaknesses:

"Most of the time I haven't had difficulty sharing the assessment and diagnosis. I'm also a very strong advocate for my son...if somebody is a little bit...apprehensive or leery about it, it doesn't matter to me because I can overcome that and just talk about...the positive things and the things that he can do and the supports we need to put in place...” (Jessica, Caregiver)

However, for those unfamiliar with assessment, the process can be quite intimidating, especially for caregivers who have heard often the weaknesses of their child. As such, the debriefing session is not always a smooth or desirable event: "the parents...find it daunting if... you're supposed to offer them a meeting with the person who conducted the assessment..." (Tom, Administrator). Becky, another administrator further elaborated: “...they're tired, they're exhausted. They don't need another report saying what their kid can't do...they don't necessarily want to come in and meet with the psychologist to go over the same thing..."

Breaking down the barriers of intimidation to facilitate open communication between school psychologists, teachers, and caregivers is paramount to information sharing. As it stands, psychologists and other allied professionals are restricted in their time to share information and resources, which can lead to a duplication of services or gaps in service delivery for children with special needs (Reddy \& Newman, 2009). This limited sharing of information and resources can leave teachers and caregivers with disjointed assessment results, leading to inappropriate planning and intervention (Reddy \& Newman).

Unique to the allied professional group, participants spoke about the need for new and improved teaching strategies as outlined by psychologists within the assessment report: "A lot of the strategies that are given are like 'Duh'...we already tried that...Some of the strategies are just really silly and stuff that we would already know and...do. We want new and improved strategies that may work [for these students]" (Catia). The specificity of strategies seemed to be of primary concern-with school personnel looking for strategies tailored specifically to the educational needs of children with FASDs. It seems that there is a concern that while the psychologist may be the expert in assessment, he/she may not be an expert on what is happening in the classroom and thus, what interventions would work well for that environment (Knoetze \& Vermoter, 2007).

Meaningful understanding. Language used in the report emerged as a key challenge of current assessment practices and was highlighted across teacher, administrator, and allied professional roles. Language that was vague, complex or inconsistent had significant implications for translation of report recommendations into action because school personnel had tremendous difficulty understanding assessment results. For example, one teacher candidly noted that the lack of comprehensible reports leads many teachers to disregard them altogether: “...teachers don’t read reports...[except] maybe at [Individualized Program Plan] time...” (Sandra). Given that the psychological report provides such critical information, it is imperative when writing to consider the education level and assessment knowledge of the teachers and caregivers responsible for receiving the information and carrying out suggested recommendations (Anastasi \& Urbina, 1997).

Another area of debate was whether reports should include "soft” language (e.g. "delay” rather than "deficit”) in describing functional and behavioral limitations. The majority of participants across roles agreed that the use of softer language leads to unrealistic expectations for improvement and pressure on teachers to help children make gains:

"They want us to do assessments every year and see that growth and when they're seeing that their child's not growing then there's got to be blame somewhere...' what is the school doing because my kid is still...[not] progressing?'...[and this is because]...the vocabulary has been very delicate in saying 'there's a delay" and that infers that at some point, if you work hard enough...you will catch up..." (Sara, Administrator).

Overall, participants spoke to the inaccessibility of report content due to complexities in language and written presentation. This finding is immensely important as it speaks to the continued disconnect between knowledge and action. If teachers and allied professionals are struggling to understand assessment results, the likelihood that related strategies will be incorporated in the classroom is limited. Knoetze and Vermoter (2007) suggest teachers gain familiarity with psychometric tests and psychologists make themselves aware of the aspects of behavioral and cognitive functioning that would be most useful to report on for school personnel and caregivers and write their reports accordingly. Assessment for intervention necessitates a bridging of the gap between the knowledge and skills of school psychologists and those of teachers and allied professionals in terms of assessment so that each stakeholder has a more holistic understanding of the assessment process (Knoetze \& Vermoter, 2007) and its ultimate goal of informing intervention.

\section{Implications and Future Directions}

This study highlights important implications and serves as a call to action for researchers, school psychologists, and school personnel. In advocating a move toward assessment for intervention, there are 3 main ideas to be emphasized: a) assessment and diagnosis are only as useful as the accommodations and supports that follow; b) the varied learning and behavioral needs of children with FASDs require assessments that are geared toward informing intervention practices in order to achieve the best possible results; and c) support for and inclusion of teachers in the assessment process is vital, recognizing their expertise and value in decision-making for programming and intervention.

The present paper emphasizes the need for a fundamental change in the purpose of assessment. Mastoras and colleagues (2011) report that concerns and complaints about assessment have lingered for more than forty years, and that little progress has been made to improve upon current practices. If school psychologists and educators are to effectively meet the needs of children affected by FASDs, a paradigm shift away from diagnostic and funding goals toward informed interventions must 
occur. It is in this way that processes can begin to evolve, allowing for greater collaboration among key professionals, improved recommendations, and monitoring of child outcomes. Stakeholders echoed many of the general feelings of dissatisfaction identified in the assessment literature, suggesting that the full potential of assessment is not being realized within the school system. To remedy this, participants suggest a muchneeded shift in perspective. Through examination of the assessment experiences and attitudes of teachers, administrators, caregivers, and allied professionals involved in working with children with FASDs, it is clear that a responsive assessment process that reflects the whole child can be a valuable catalyst to effective intervention practices.

Assessment must be re-conceptualized as a process of initiating intervention. By using this lens to view assessment, assessment moves beyond simply attaching a diagnosis to a child toward understanding the whole child within their environment in order to best match their needs to the resources available. This perspective then opens the door to some of the needs for teamwork, collaboration, clear communication, use of lay terminology, and consideration of both strengths and deficits of the child with an FASD. This provides the opportunity to approach assessment in a proactive way; thus, avoiding the "wait to fail" model and moving toward a "planning for success" model. An assessment may or may not result in diagnosis, and yet many affected children require specialized services and supports to succeed in school. The goal then should be to discover and remediate the affected child's underlying difficulties, using assessment information to inform evidence-based instruction and intervention (Fletcher et al., 2004).

All professionals working with the affected child must be invited to contribute to the assessment at several points, providing understanding and seeking solutions and strategies. By moving to an assessment for intervention framework, a fluid process of informed responding is created that recognizes expertise comes from many places, including both home and school, which may then lead to improved consistency in implementation of recommendations. However, moving to this approach also means that more time must be allotted to teachers and allied professionals to collaborate and plan next steps. Increased recognition of the proactive potential of assessment is also required so responses can be initiated prior to crisis. To enable these changes, it is crucial that both service providers and schools recognize this potential and allocate resources (i.e., time and money). Those involved with the education system must insist on this level of integrated service if this proposed shift is to take place and we are to move forward in assessment and intervention.

\section{Limitations}

Due to the special nature of research with FASD populations, several limitations in methodology are noted. First, the use of snowball sampling, while convenient, can produce community bias. Participants are not randomly selected and thus, may affect the representativeness of FASD stakeholders. Those identified have been vocal in the field and may present with more extreme experiences than the average teacher or allied professional working with affected children. A second limitation is the lack of geographical and cultural representativeness of participants in this study since school personnel worked within a single, public school district with children with FASDs of little ethnic variability (e.g., Caucasian or Aboriginal). To address these limitations, researchers tried to select participants from as many different schools and neighborhoods as possible and organized focus group sessions mixing stakeholders to limit the familiarity of participants within each group. Third, the use of focus groups can lead to questions of validity in that participants may be influenced by the researcher and/or other participants, providing responses that will be viewed favorably rather than true experiences (i.e., socially desirability effect). It is believed that providing summaries to participants and allowing them a second opportunity to add to or change their responses helped to enhance the trustworthiness of the data.

\section{Conclusion}

Without the fundamental shift toward assessment for intervention, the needs of children with FASDs will continue to remain unmet. The inability to meet the varied needs of this unique population often results in frustration and discouragement for the children and their teachers, and can lead to an alignment with marginalized groups and other disruptive school experiences for the individuals affected by FASDs-all secondary disabilities frequently reported for this population (e.g., Streissguth et al., 2004). Considering the importance of intervention and support services for successful outcomes of children with FASDs, it is imperative that current assessment practices specific to this population be detailed, highlighting key strengths and challenges. The recognition of important strengths and weaknesses in the assessment process helps in the identification of avenues for change as we move toward assessment for intervention with the goal of successful outcomes for affected children.

\section{REFERENCES}

Ackerman, M. E. (1998). Fetal Alcohol Syndrome: Implications for educators. ERIC Document Reproduction Service No. ED426560. Chatham, VA: Rivermont School Central Health.

Anastasi, A., \&Urbina, S. (1997). Psychological testing. New Jersey: Prentice Hall.

Blackburn, C., Carpenter, B., \& Egerton, J. (2010). Shaping the future for children with foetal alcohol spectrum disorders. British Journal of Learning Support, 25, 139-145. doi:10.1111/j.1467-9604.2010.01452.x

Borghese, N., \& Cole, E. (1994). Psychoeducational recommendations: Perceptions of school psychologists and classroom teachers. Canadian Journal of School Psychology, 10, 70-87.

Burd, L., Klug, M. G., Martsolf, J. T., \& Kerbeshian, J. (2003). Fetal alcohol syndrome: Neuropsychiatric phenomics. Neurtoxicology \& Teratology, 25, 697-705. doi:10.1016/j.ntt.2003.07.014

Chudley, A. E., Conry, J., Cook, J. L., Loocke, C., Rosales, T., \& LeBlanc, N. (2005). Fetal alcohol spectrum disorder: Canadian guidelines for diagnosis. Canadian Medical Association Journal, 172, 121. doi:10.1503/cmaj.1040302

Cheramie, G., Goodman, B., Santos, V., \& Webb, E. (2007). Teacher perceptions of psychological reports submitted for emotional disturbance eligibility. Journal of Education and Human Development, 1, 18.

Clark, E. C. (2012). Assessment of a school-based intervention for elementary school students diagnosed with fetal alcohol spectrum disorder (FASD). Ph.D. Dissertation, Vancouver, BC: University of British Columbia.

Creswell, J. W. (2012). Educational research: Planning, conducting, and evaluating quantitative and qualitative research (4th ed.). Boston, MA: Pearson.

Creswell, J. W. (2013). Qualitative inquiry \& research design ( $3^{\text {rd }}$ ed.). 
Thousand Oaks, CA: Sage.

Duquette, C., Stodel, E., Fullarton, S., \& Hagglund, K. (2006a). Persistence in high school: Experiences of adolescents and young adults with fetal alcohol spectrum disorder. Journal of Intellectual \& Developmental Disability, 31, 219-231. doi:10.1080/13668250601031930

Duquette, C., Stodel, E., Fullarton, S., \& Hagglund, K. (2006b). Teaching students with developmental disabilities: Tips from teens and young adults with fetal alcohol spectrum disorder. Teaching Exceptional Children, 39, 28-31.

Fletcher, J. M., Foorman, B. R., Boudousquie, A., Barnes, M. A., Schatschneider, C., \& Francis, D. J. (2002). Assessment of reading and learning disabilities: A research-based intervention-oriented approach. Journal of School Psychology, 40, 27-63. doi:10.1016/S0022-4405(01)00093-0

Fletcher, J. M., Francis, D. J., Shaywitz, S. E., Lyon, G. R., Foorman, B. R., Stuebing, K. K., \& Shaywitz, B. A. (1998). Intelligent testing and the discrepancy model for children with learning disabilities. Learning Disabilities Research \& Practice, 13, 186-203.

Gahagan, S., Telfair Sharpe, T., Brimacombe, M., Fry-Johnson, Y., Brenneman, G., Levine, R., Mengel, M., O’Connor, M., Paley, B., \& Adubato, S. (2006). Pediatricians' knowledge, training, and experience in the care of children: With fetal alcohol syndrome. Pediatrics, 118, e657-e668. doi:10.1542/peds.2005-0516

Glaser, B. G., \& Strauss, A. L. (1967).The discovery of grounded theory. Chicago, IL: Aldine.

Green, J. H. (2007). Fetal alcohol spectrum disorder: Understanding the effects of prenatal alcohol exposure and supporting students. Journal of School Health, 77, 103-108. doi:10.1111/j.1746-1561.2007.00178.x

Groth-Marnat, G. (2009). The five assessment issues you meet when you go to heaven. Journal of Personality Assessment, 91, 303-310. doi:10.1080/00223890902935662

Harris, S. R., MacKay, L. L. J., \& Osborn, J. A. (1995). Autistic behaviors in offspring of mothers abusing alcohol and other drugs: A series of case reports. Alcoholism: Clinical and Experimental Research, 19, 660-665. doi:10.1111/j.1530-0277.1995.tb01564.x

Harvey, V. (1997). Improving the readability of psychological reports. Professional Psychology: Research and Practice, 28, 271-274. doi:10.1037/0735-7028.28.3.271

Harvey, V. (2006).Variables affecting the clarity of psychological reports. Journal of Clinical Psychology, 62, 5-18. doi:10.1002/jclp.20196

Healthy Child Manitoba (2010). What early childhood educators and caregivers need to know about Fetal Alcohol Spectrum Disorders (FASDs). URL (last checked 20 June 2012) http://www.gov.mb.ca/healthychild/fasd/fasdearly_en.pdf

Howell, K. K., Lynch, M. E., Platzman, K. A., Smith, G. H., \& Coles, C. D. (2006). Prenatal alcohol exposure and ability, academic achievement, and school functioning in adolescence: A longitudinal followup. Journal of Pediatric Psychology, 31, 116-126. doi:10.1093/jpepsy/jsj029

Jimerson, S. R., Sharkey, J. D., Nyborg, V., \& Furlong, M. J. (2004). Strength-based assessment and school psychology: A summary and synthesis. The California School Psychologist, 9, 9-19.

Job, J., Pasula-Carter, B., Brandell, D., Pei, J., Poth, C., \& Macnab, J. (2011). Toward better collaboration in the education of students with fetal alcohol spectrum disorders: Perspectives of teachers, administrators, caregivers, and allied professionals. Hawaii International Conference on Education in Honolulu, Honolulu, Hawaii.

Job, J. M., Poth, C. A., Pei, J., Caissie, B., Brandell, D., \& Macnab, J. (2013). Toward better collaboration in the education of students with fetal alcohol spectrum disorders: Integrating the voices of teachers, administrators, caregivers, and allied professionals. Qualitative Research in Education, 2, 38-64.

Kalberg, W., \& Buckley, D. (2007). FASD: What types of intervention and rehabilitation are useful? Neuroscience and Biobehavioral Reviews, 31, 278-285. doi:10.1016/j.neubiorev.2006.06.014

Kelly, S. J., Day, N., \& Streissguth, A. P. (2000). Effects of prenatal alcohol exposure on social behaviour in humans and other species. Neurotoxicology and Teratology, 22, 143-149.
doi:10.1016/S0892-0362(99)00073-2

Klin, A., Saulnier, C. D., Tsatsanis, K. D., \& Volkmar, F. R. (2005) Clinical evaluation in autism spectrum disorders: Psychological assessment within a transdisciplinary framework. In F. R. Volkmar, R. Paul, A. Klin, \& D. Cohen (Eds.), Handbook of autism and pervasive developmental disorders (3rd ed.). Hoboken, NJ: John Wiley \& Sons.

Knoetze, J., \& Vermoter, C. (2007). Communication of psycho-educational assessment results: Remedial teachers' reading of assessment reports. South African Journal of Education, 27, 1-18.

Koren, G., Nulman, I., Chudley, A. E., \& Loocke, C. (2003). Fetal alcohol spectrum disorder. Canadian Medical Association Journal, 169, 1181-1185.

Krueger, R. A., \& Casey, M. A. (2000). Focus groups: A practical guide for applied research. Thousand Oaks, CA: Sage.

Lincoln, Y. S., \& Guba, E. G. (1985). Naturalistic inquiry. Beverly Hills, CA: Sage Publications.

Malisza, K. L., Allman, A. A., Shiloff, D., Jakobson, L., Longstaffe, S., \& Chudley, A. E. (2005). Evaluation of spatial working memory function in children and adults with Fetal Alcohol Spectrum Disorders: A functional magnetic resonance imaging study. Pediatric Research, 58, 1150-1157. doi:10.1203/01.pdr.0000185479.92484.a1

Mastoras, S., Climie, E., McCrimmon, A., \& Schwean, V. (2011). A C.L.E.A.R. approach to report writing: A framework for improving the efficacy of psychoeducational reports. Canadian Journal of School Psychology, 26, 127-147. doi:10.1177/0829573511409722

Merriam, S. B. (2009). Qualitative research: A guide to design and implementation. San Francisco, CA: Jossey-Bass.

Paley, B., \& O’Connor, M. J. (2009). Interventions for children with fetal alcohol spectrum disorders: Treatment approaches and case management. Developmental Disabilities Research Reviews, 15, 258267. doi:10.1002/ddrr.67

Paley B., O’Connor, M. J., Baillie, S. et al. (2009). Integrating case topics in medical school curriculum to enhance multiple skill learning: Using fetal alcohol spectrum disorders as an exemplary case. Academic Psychiatry, 33, 143-148. doi:10.1176/appi.ap.33.2.143

Patton. M. Q. (2002). Qualitative research and evaluation methods (3rd ed.). Thousand Oaks, CA: Sage Publications.

Pei, J., Denys, K., Hughes, J., \& Rasmussen, C. (2011). Mental health issues in fetal alcohol spectrum disorder. Journal of Mental Health, 20, 438-448. doi:10.3109/09638237.2011.577113

Pei, J. Job, J. M., Poth, C., O’Brien-Langer, A., \& Tang, W. (2013). Pre-service teachers' knowledge and attitudes about students with fetal alcohol spectrum disorders. Manuscript in preparation.

Poth, C., Pei, J., Job, J. M., \& Wyper, K. (2013). Fostering a focus on the whole student: Implications for classroom practice. Manuscript in preparation.

Public Health Agency of Canada (2011). Assessment and diagnosis of FASD among adults: A national and international systematic review. http://www.phacaspc.gc.ca/fasd-etcaf/index-eng.php

Rasmussen, C. (2005). Executive functioning and working memory in Fetal Alcohol Spectrum Disorder. Alcoholism: Clinical and Experimental Research, 29, 1359-1367. doi:10.1097/01.alc.0000175040.91007.d0

Reddy, L., \& Newman, E. (2009). School-based programs for children with emotional disturbance: Obstacles to program design and implementation and guidelines for school practitioners. Journal of Applied School Psychology, 25, 169-186. doi:10.1080/15377900802486971

Rhee, S., Furlong, M., Turner, J., \& Harari, I. (2001). Integrating strengthbased perspectives in psychoeducational evaluations. The California School Psychologist, 6, 5-17.

Ryan, S., \& Ferguson, D. L. (2006a). On, yet under, the radar: Students with fetal alcohol syndrome disorder. Exceptional Children, 72, 363365.

Ryan, S., \& Ferguson, D. L. (2006b). The person behind the face of fetal alcohol spectrum disorder: Student experiences and family and professionals' perspectives on FASD. Rural Special Education Quarterly, 25, 32-40.

Seligman, M., Linley, P., \& Joseph, A. (2004). Positive psychology in 
practice. Hoboken, NJ: Wiley.

Steinhausen, H., Willms, J., Metzke, C.W., \& Spohr, H. (2003). Behavioural phenotype in foetal alcohol syndrome and foetal alcohol effects. Developmental Medicine and Child Neurology, 45, 179-182. doi:10.1111/j.1469-8749.2003.tb00927.x

Streissguth, A., Bookstein, F., Barr, H., Sampson, P., O’Malley, K., \& Young, J. (2004). Risk factors for adverse life outcomes in fetal alcohol syndrome and fetal alcohol effects. Journal of Developmental andBehavioral Pediatrics, 25, 228-238.

Streissguth, A. P., \& Kanter, J. (1997). The challenges of Fetal Alcohol Syndrome: Overcoming secondary disabilities. Seattle, WA: University of Washington Press.
Temple University Institute on Disabilities (2003). What we are learning about autism/pervasive developmental disorder: Evolving dialogues and approaches to promoting development and adaptation (2nd ed.). New Cumberland, PA: Contract Consultants, Inc.

Terjesen, M. D., Jacofsky, M., Froh, J., \& DiGiuseppe, R. (2004). Integrating positive psychology into schools: Implications for practice. Psychology in the Schools, 41, 163-172. doi:10.1002/pits.10148 